\title{
Produção de repolho em função de doses e fontes de potássio em cobertura
}

\section{Yield of cabbage depending on rates and sources of potassium in top dressing}

\author{
Carla Verônica Correa ${ }^{1}$; Antonio Ismael Inácio Cardoso ${ }^{2 *}$; \\ Marina de Toledo Rodrigues Claudio ${ }^{3}$
}

\begin{abstract}
Resumo
O objetivo desta pesquisa foi avaliar o efeito de doses e fontes de potássio em cobertura na produção de repolho híbrido Kenzan. Foram conduzidos dois experimentos (15/07 a 22/11/2010 e 28/09/2010 a 27/01/2011) e avaliados 9 tratamentos, resultantes do fatorial 4 doses $\left(45 ; 90 ; 135\right.$ e $180 \mathrm{~kg} \mathrm{ha}^{-1}$ de $\mathrm{K}_{2} \mathrm{O}$ ) х 2 fontes (cloreto e sulfato de potássio) +1 testemunha (sem potássio em cobertura), no delineamento experimental de blocos casualizados, com 4 repetições. Após a colheita, foram avaliados a massa fresca e seca da cabeça e das folhas externas, número de folhas, diâmetro e altura da cabeça. Apenas no primeiro experimento foram avaliadas características químicas do solo ao final do ciclo e teores de macro e micronutrientes na planta. Observou-se que as doses e fontes de potássio em cobertura não influenciaram a maioria das características avaliadas. Os teores de potássio na planta aumentaram linearmente com as doses de cloreto de potássio. Os resultados obtidos demonstram que, provavelmente, não é necessária a aplicação de potássio em cobertura quando já se faz a adubação de plantio com este nutriente, apesar das recomendações existentes para a cultura.
\end{abstract}

Palavras chave: Brassica oleraceae var. capitata, cloreto, sulfato

\begin{abstract}
The objective of this research was to evaluate the effects of rates and sources of potassium in top dressing on yield of cabbage hybrid Kenzan. Two experiments were conducted (15/07 to 22/11/2010 and 28/09/2010 to 27/01/2011) and nine treatments, resulted from a factorial 4 rates $(45 ; 90 ; 135$ and $180 \mathrm{~kg} \mathrm{ha}^{-1}$ of $\left.\mathrm{K}_{2} \mathrm{O}\right) \times 2$ sources $\left(\mathrm{KCl}\right.$ and $\left.\mathrm{K}_{2} \mathrm{SO}_{4}\right)+1$ control (without $\mathrm{K}$ in top dressing) were evaluated at randomized block design, with 4 replicates. After the harvest, fresh and dry weight of cabbage head and of external leaves; leaf number (from cabbage and external); diameter and height of cabbage head were evaluated. It was evaluated soil chemical characteristics at the end of first experiment and content of macro and micronutrients in plants. It was observed that potassium rates and sources did not influence most of evaluated characteristics. $\mathrm{K}$ content in plant increased linearly with $\mathrm{KCl}$ application. Results obtained show that, probably, it is not necessary application of $\mathrm{K}$ in top dressing when base fertilization is done with this nutrient, besides existing recommendations for this crop.
\end{abstract}

Key words: Brassica oleraceae var. capitata, chloride, sulfate

\footnotetext{
${ }^{1}$ Discente em Agronomia, Dept ${ }^{\circ}$ de Produção Vegetal, Setor Horticultura, Faculdade de Ciências Agronômicas, Universidade Estadual Paulista, UNESP, Botucatu, SP. E-mail: cvcorrea@fca.unesp.br

${ }^{2}$ Eng $^{\mathrm{o}} \mathrm{Agr}^{\mathrm{o}}$, Prof. Adjunto do Dept ${ }^{\mathrm{o}}$ de Produção Vegetal, Setor Horticultura da UNESP, Botucatu, SP. Bolsista de Produtividade do CNPq. E-mail: ismaeldh@fca.unesp.br

${ }^{3}$ Eng $^{\mathrm{a}}$ Agr ${ }^{\mathrm{a}}$, Discente de Mestrado, Dept ${ }^{\circ}$ de Produção Vegetal, Setor Horticultura, Faculdade de Ciências Agronômicas, UNESP, Botucatu, SP. E-mail: marinatoledo@fca.unesp.br

*Autor para correspondência
} 


\section{Introdução}

O repolho (Brassica oleraceae var. capitata) é uma olerícola muito consumida e de alto valor nutritivo. Pode ser cultivado o ano todo devido às adaptações dos híbridos às diversas condições climáticas (FILGUEIRA, 2008).

As hortaliças são exigentes em potássio, sendo este o macronutriente mais extraído pela maioria delas, inclusive o repolho (AQUINO et al., 2009). O potássio favorece a formação e translocação de carboidratos e o uso eficiente da água pela planta; equilibra a aplicação de nitrogênio e melhora a qualidade do produto e, consequentemente, o valor de mercado (FILGUEIRA, 2008). Este autor recomenda, para solos de fertilidade mediana ou baixa, a aplicação de 40; 150 a 300 e 100 a 150 kg ha $^{-1}$ de $\mathrm{N}, \mathrm{P}_{2} \mathrm{O}_{5}$ e $\mathrm{K}_{2} \mathrm{O}$, respectivamente, aplicados no sulco de transplante das mudas. Já Raij et al. (1997) recomendam 60; 400 a 600 e 180 a 240 de N, $\mathrm{P}_{2} \mathrm{O}_{5}$ e $\mathrm{K}_{2} \mathrm{O}$, respectivamente, e complementar com adubação em cobertura com 15 a $200 \mathrm{~kg} \mathrm{ha}^{-1}$ de $\mathrm{N} \mathrm{e}$ 60 a $120 \mathrm{~kg} \mathrm{ha}^{-1}$ de $\mathrm{K}_{2} \mathrm{O}$, parcelando em 4 vezes, aos $15,30,45$ e 60 dias após o transplante.

As necessidades de potássio para o crescimento ideal das plantas situam-se na faixa de 20 a $50 \mathrm{~g} \mathrm{~kg}^{-1}$ de potássio na matéria seca das partes vegetativas da planta, frutos e tubérculos. Entretanto, as plantas apresentam a capacidade de absorver quantidades de potássio superiores às suas necessidades, o que comumente é denominado de "consumo de luxo" (FERNANDES, 2006).

A adubação excessiva com potássio pode levar ao aumento na concentração salina do solo, redução na absorção de outros cátions, principalmente cálcio e magnésio, promovendo redução na produtividade da cultura e perdas por lixiviação (RAIJ et al., 1997). Segundo Fernandes (2006), pesquisas realizadas em solos brasileiros não tem apresentado acentuada resposta à fertilização com esse nutriente, provavelmente devido a fatores como teores de potássio já adequados no solo, presença de minerais fontes de potássio, contribuição de formas não trocáveis do elemento, entre outros. Segundo Filgueira (2008), poucas olerícolas respondem à aplicação de potássio em cobertura sendo que, na literatura brasileira, existem poucas informações referentes à aplicação de potássio em cobertura para o cultivo de hortaliças (LUZ et al., 2009).

Quanto ao enxofre (S), apesar da recomendação de adubação para o repolho por Raij et al. (1997) com 30 a $60 \mathrm{~kg} \mathrm{ha}^{-1}$ de $\mathrm{S}$ no plantio e também por Filgueira (2008), poucos trabalhos foram realizados no intuito de se verificar a resposta da cultura a este nutriente. No entanto, Nahas, Delfino e Assis (1997) obtiveram aumento na massa de cabeça ao utilizar esse nutriente.

Alguns trabalhos têm comprovado a importância do nitrogênio em cobertura para aumentar a produção e qualidade de repolho (HUETT; DETTMANN, 1989; AQUINO et al., 2005a, 2005b; 2009; DIN, QASIM; ALAM, 2007; MOREIRA; VIDIGAL, 2011; MOREIRA et al., 2011), porém, não há relatos que suportem esta recomendação para o potássio, apesar da importância deste nutriente para as brássicas.

Considerando a necessidade de se definir a necessidade de adubação potássica em cobertura para a cultura do repolho, o presente trabalho teve por objetivo avaliar o efeito de doses e fontes de potássio aplicados em cobertura.

\section{Material e Métodos}

Os experimentos foram conduzidos no município de São Manuel-SP (22 $46^{\prime}$ de latitude sul, $48^{\circ} 34^{\prime}$ de longitude oeste e altitude de $740 \mathrm{~m}$ ). O clima predominante, segundo a classificação de Köppen, é tipo Cfa, temperado quente (mesotérmico) úmido e a temperatura média do mês mais quente é superior a $22{ }^{\circ} \mathrm{C}$ (CUNHA; MARTINS, 2009) e precipitação média anual de $1.377 \mathrm{~mm}$.

Foram realizados dois experimentos, sendo o primeiro de $15 / 07$ a 22/11/2010 e o segundo de 26/09/2010 a 27/01/2011. 
O solo é um Latossolo Vermelho Distrófico Típico. As principais características químicas do solo foram avaliadas a partir de amostras coletadas em diferentes pontos, retirando solo a uma profundidade de $0-20 \mathrm{~cm}$. Para o experimento 1 foram obtidos os seguintes valores: $\mathrm{pH}$ : 6,6; M.O: $12 \mathrm{~g} \mathrm{dm}^{-3} ; \mathrm{P}_{\text {resina: }} 17 \mathrm{mg} \mathrm{dm}^{-3}$; $\mathrm{H}+\mathrm{Al}: 9 \mathrm{mmolc} \mathrm{dm}-$ 3; K: 1,2 mmolc dm ${ }^{-3}$; Ca: 45 mmolc dm ${ }^{-3}$; Mg: 18 mmolc dm ${ }^{-3}$; SB: 72 mmolc dm ${ }^{-3}$; CTC: 82 mmolc $\mathrm{dm}^{-3}$ e V: $88 \%$. Para o Experimento 2 os resultados foram: $\mathrm{pH}$ : 6,4; M.O: $11 \mathrm{~g} \mathrm{dm}^{-3}$; $\mathrm{P}_{\text {resina: }} 13 \mathrm{mg} \mathrm{dm}^{-3}$; $\mathrm{H}+\mathrm{Al}: 12$ mmolc dm $\mathrm{dm}^{-3} ; \mathrm{K}: 1,9 \mathrm{mmolc} \mathrm{dm}^{-3}$; Ca: 20 mmolc dm${ }^{-3}$; Mg: 10 mmolc dm ${ }^{-3}$; SB: 32; CTC: 44 e V: $82 \%$.

Assim, baseando-se nas recomendações de Raij et al. (1997), foram aplicados $240 \mathrm{~kg} \mathrm{ha}^{-1}$ de potássio, $120 \mathrm{~kg} \mathrm{ha}^{-1}$ de nitrogênio e $420 \mathrm{~kg} \mathrm{ha}^{-1}$ de fósforo e $4 \mathrm{~kg} \mathrm{~m}^{-2}$ de composto orgânico (base úmida, com umidade de 37,9\%) de marca comercial Provaso ${ }^{\circledR}$ na adubação de plantio em área total dos canteiros. Como fonte de nitrogênio, potássio e fósforo, foram utilizados a uréia, o cloreto de potássio e o superfosfato triplo, respectivamente. Foi feita análise química do composto (base úmida), obtendose os seguintes resultados: umidade $\left(65^{\circ} \mathrm{C}\right): 37,9 \%$; $\mathrm{N}: 0,43 \% ; \mathrm{P}_{2} \mathrm{O}_{5}: 0,62 \% ; \mathrm{K}_{2} \mathrm{O}: 0,48 \%$; Ca: $1,61 \%$; Mg: 0,17\%; S: 0,2\%. Esta adubação foi realizada no dia 13/08/2010 para o experimento 1 e para o experimento 2 foi realizada no dia 20/10/2010. Nos dois experimentos, foi realizada nova análise do solo no dia do transplante.

Foram fornecidos, em cobertura, $108 \mathrm{~kg} \mathrm{ha}^{-1}$ de nitrogênio (média das doses recomendadas por Raij et al., 1997), na forma de uréia em todos os tratamentos e a dose de potássio foi variável em função do tratamento. Foram nove tratamentos, resultantes do fatorial $4 \times 2$, sendo quatro doses (45; 90; 135 e $180 \mathrm{~kg} \mathrm{ha}^{-1} \mathrm{de}_{2} \mathrm{O}$ ) x duas fontes (cloreto e sulfato de potássio) +1 testemunha (sem potássio em cobertura), no delineamento experimental de blocos casualizados, com quatro repetições e 12 plantas por parcela $\left(3,84 \mathrm{~m}^{2}\right)$, sendo avaliadas seis plantas. Estas doses englobam e ultrapassam as doses recomendadas por Raij et al. (1997) para a cultura, que varia de 60 a $120 \mathrm{~kg} \mathrm{ha}^{-1}$ de $\mathrm{K}_{2} \mathrm{O}$. A adubação em cobertura foi feita de acordo com os tratamentos aos 15, 30, 45 e 60 dias após o transplante, em ambos os experimentos, colocandose $1 / 4$ do total em cada aplicação, junto à planta.

Como o sulfato de potássio apresenta cerca de $16 \%$ de enxofre, os tratamentos com esta fonte forneceram, em média, 15; 30; 45 e $60 \mathrm{~kg} \mathrm{ha}^{-1}$ de enxofre.

A semeadura foi realizada em bandejas de poliestireno expandido ("isopor") com 242 células, com substrato comercial Plantmax ${ }^{\circledR}$ nos dias 22/07/10 e 26/09/2010 para os experimentos 1 e 2 , respectivamente. $\mathrm{O}$ transplante ocorreu quando as mudas apresentavam de 3 a 4 folhas definitivas e foi realizado nos dias 20/08/2010 e 28/10/2010 para os experimentos 1 e 2 , respectivamente, com espaçamento de $0,8 \times 0,4 \mathrm{~m}$. Os tratos culturais compreenderam a capina, irrigação por aspersão e a utilização de inseticida para o controle de pulgões (Brevicoryne brassicae), traça (Plutella xylostella) e curuquere (Ascia monuste orseis) das brássicas. As colheitas foram realizadas nos dias 21/11/2011 (experimento 1) e 18/01/2011 (experimento 2). Utilizou-se o híbrido Kenzan, repolho do tipo verde de folhas lisas, tradicional e de alta uniformidade. Apresenta cabeças de tamanho, diâmetro e altura médios.

Logo após a colheita, foram avaliados a massa fresca e seca da cabeça e das folhas externas à cabeça; número de folhas (internas e externas); diâmetro e altura da cabeça. Para obtenção da massa foi utilizada balança semi-analítica, expressando os valores em gramas por planta e para o diâmetro e altura foi utilizado paquímetro digital, sendo os resultados expressos em centímetros.

Apenas no primeiro experimento foram coletadas amostras de solo (profundidade de 0 $20 \mathrm{~cm}$ ) ao final do ciclo em cada parcela (quatro sub amostras junto às plantas por parcela) para determinação das seguintes características: $\mathrm{pH}$, 
matéria orgânica, K, S, P, Ca e Mg. As amostras de solo foram secas em estufas e analisadas conforme metodologia preconizada por Raij e Quagio (1983). Após a colheita, as plantas, apenas as folhas internas que formam o repolho, foram lavadas em água deionizada e colocados em estufa com circulação forçada de ar à temperatura de $65^{\circ} \mathrm{C}$. Após a pesagem, o material total, folhas internas e externas, foi moído e digerido para determinação dos teores de N, P, K, Ca, Mg, S, Fe, B, Zn e Mn, conforme metodologias apresentadas por Malavolta, Vitti e Olvieira (1997).

Os dados foram submetidos à análise de variância. Se significativo (teste $\mathrm{F}$ para doses, $\mathrm{p}<0,05$ ), foram realizadas análises de regressão e ajustadas equações polinomiais, de acordo com os coeficientes de determinação. Com relação às fontes, foram comparadas pelo teste de Tukey $(\mathrm{p}<0,05)$.

\section{Resultados e Discussão}

Observou-se que as doses e fontes de potássio em cobertura não influenciaram as características avaliadas, exceto os teores de potássio e enxofre na planta e teor de enxofre no solo ao final do ciclo.

Para massa fresca da cabeça os valores médios foram de 1423g (com coeficiente de variação $\mathrm{CV}=5,6 \%)$ para o experimento 1 e de $961 \mathrm{~g}(\mathrm{CV}$ $=9,5 \%$ ) para o experimento 2 . Os valores obtidos estão dentro da faixa, ou pouco inferiores, em relação aos obtidos por Oliveira et al. (2003), por Aquino et al. (2005a) e por Silva et al. (2011) e superiores aos de Moreira et al. (2011), pois os valores dependem do genótipo, do espaçamento, das condições climáticas, dentre outros fatores. No entanto, os valores estão dentro da faixa considerada como ideal para a comercialização, segundo Aquino et al. (2005a), que é de 1,0 a 1,5 kg por cabeça.

Observou-se menor massa fresca no experimento 2 em relação ao experimento 1 , provavelmente devido às condições climáticas, caracterizadas por elevadas temperaturas e precipitação (446,5 e 618,0mm para os experimentos 1 e 2, respectivamente) terem sido mais favoráveis a manifestação da bacteriose causadora de podridão negra (X. campestris pv. campestris) no experimento 2. Segundo Peruch, Michereff e Araújo (2006), a presença desta bactéria pode ser fator limitante à cultura, reduzindo a produtividade. Devido a estas condições climáticas e fitopatológicas, houve a necessidade de antecipar a colheita no experimento 2 em torno de 10 dias para evitar a perda das plantas por apodrecimento, o que também contribuiu para a menor massa das cabeças.

Nahas, Delfino e Assis (1997) relataram aumento na massa de cabeça com a utilização de diferentes fontes de enxofre (gesso e sulfato de amônia) em relação à testemunha, o que não ocorreu na presente pesquisa onde se utilizou o enxofre em cobertura nos tratamentos com sulfato de potássio.

Também não foram observadas diferenças significativas para a matéria seca da cabeça, tanto para as doses como para fontes. Os valores médios no experimento 1 foram de $93 \mathrm{~g}(\mathrm{CV}=20,5 \%)$ e de $56 \mathrm{~g}(\mathrm{CV}=18,8 \%)$ no experimento 2. Cavarianni (2008) obteve matéria seca de $117,3 \mathrm{~g}$ por planta em uma densidade de 31.250 plantas ha $^{-1}$, utilizando o híbrido Astrus (repolho verde) e, ao utilizar o híbrido Red Jewel (repolho roxo), obteve 58,3g na densidade de 31.250 plantas e 41,6g quando usou a densidade de 46.875 plantas ha ${ }^{-1}$, ou seja, valores superiores ao obtido neste trabalho considerandose o repolho "verde" e inferiores com o "roxo", demonstrando, mais uma vez, a diferença existente entre os híbridos avaliados por cada autor, assim como em diferentes ambientes.

A massa fresca e seca das folhas externas por planta apresentaram valores médios de 933g (CV $=9,1 \%)$ e de $104 \mathrm{~g}(\mathrm{CV}=18,0 \%)$ no experimento 1 , respectivamente e de $583 \mathrm{~g}(\mathrm{CV}=23,0 \%)$ e $58 \mathrm{~g}$ $(\mathrm{CV}=18,8 \%)$ no experimento 2 , respectivamente. A média das folhas internas por planta foi de 42 $(\mathrm{CV}=5,6 \%)$ e $40(\mathrm{CV}=9,5 \%)$ nos experimentos 
1 e 2, respectivamente. Já o das externas foi igual nos dois experimentos, 23 folhas. A média do diâmetro transversal da cabeça foi de $17 \mathrm{~cm}(\mathrm{CV}=$ $6,9 \%)$ no experimento 1 e de $15 \mathrm{~cm}(\mathrm{CV}=8,0 \%)$ no experimento 2. Para a altura da cabeça os valores médios foram de $12 \mathrm{~cm}(\mathrm{CV}=7,6 \%)$ e $11 \mathrm{~cm}(\mathrm{CV}=$ $7,2 \%$ ) para os experimentos 1 e 2 , respectivamente. Novamente, os valores obtidos estão próximos aos obtidos por outros autores (OLIVEIRA et al., 2003; AQUINO et al., 2005a; MOREIRA; VIDIGAL, 2011; MOREIRA et al., 2011).

Considerando-se todas estas características avaliadas da planta, principalmente a massa da cabeça que é a principal característica na comercialização, não se observou vantagem na aplicação de potássio, assim como enxofre, em cobertura na cultura do repolho. Provavelmente, em solos com teores baixos ou médios de potássio apenas a adubação básica no plantio com NPK associada à adubação orgânica pode ser suficiente para suprir as necessidades da cultura. Ressalta-se que o teor inicial de potássio no solo $\left(1,2\right.$ e 1,9 $\mathrm{mmol}_{\mathrm{c}} \mathrm{dm}^{-3}$, nos experimentos 1 e 2, respectivamente) é considerado baixo por Raij et al. (1997). Porém, após a adubação de plantio recomendada, elevou-se o teor para um valor (4,1 e 3,2 $\mathrm{mmol}_{\mathrm{c}} \mathrm{dm}^{-3}$, nos experimentos 1 e 2 , respectivamente) considerado alto por estes mesmos autores e este resultado pode ter sido responsável por não se obter resposta com a adubação potássica em cobertura para as características avaliadas. Destaca-se, também, que o potássio, apesar de ser encontrado em apenas uma pequena porção contida na matéria orgânica, está presente na forma livre, sendo prontamente liberado para o solo (KIEHL, 1985). Magro et al. (2010) comprovaram que o composto orgânico pode ser fonte deste nutriente em estudo com doses de composto orgânico (0 a $120 \mathrm{t} \mathrm{ha}^{-1}$, sem adição de potássio no plantio e em cobertura) onde obtiveram aumento no teor de potássio no solo ao final do ciclo. Portanto, apesar de Raij et al. (1997) recomendarem aplicar de 60 a $120 \mathrm{~kg}$ de $\mathrm{K}_{2} \mathrm{O}$ ha- ${ }^{-1}$ em cobertura, para as condições deste experimento somente a adubação de plantio foi suficiente para se alcançar boa produção de repolho. A aplicação de potássio em cobertura também não afeta a produção de abobrinha (ARAÚJO, 2011) e ervilha torta (SALATA et al., 2011), assim como as características vegetativas de mudas de abobrinha (HIGUTI et al., 2010).

Quanto às características químicas do solo ao final do ciclo, não foram obtidas diferenças significativas tanto para as doses como para as fontes para $\mathrm{pH}$ (média $6,9, \mathrm{CV}=2,3 \%$ ) e matéria orgânica (média 12,8 $\mathrm{g} \mathrm{dm}^{-3}, \mathrm{CV}=10,0 \%$ ). Também não se observou diferença significativa para os teores de $\mathrm{P}\left(88 \mathrm{mg} \mathrm{dm}{ }^{-3}, \mathrm{CV}=21,2 \%\right), \mathrm{Ca}$ e $\mathrm{Mg}$, com médias de $47(\mathrm{CV}=16,6 \%)$ e $18(\mathrm{CV}$ $=1,0 \%)$ mmolc $\mathrm{dm}^{-3}$, respectivamente, mostrando que o potássio e o enxofre aplicados em cobertura não influenciam estes nutrientes no solo. Não se obteve diferença no teor de $\mathrm{S}$ ao se utilizar cloreto de potássio, com média de $11 \mathrm{mg} \mathrm{dm}^{-3}$, o que já era esperado, pois este adubo não é fonte de enxofre. Já o sulfato de potássio, por ser fonte deste nutriente, resultou em aumento linear (Figura 1), com valores significativamente superiores aos do cloreto para todas as doses.

Em relação ao potássio, embora tenham sido aplicadas diferentes doses não foram observadas diferenças nem mesmo em relação à testemunha ( $0 \mathrm{~kg} \mathrm{ha}^{-1}$ de $\mathrm{K}_{2} \mathrm{O}$ ), com média de 2,2 mmolc dm 3. Isso provavelmente possa ser explicado pela susceptibilidade desse nutriente à lixiviação, lembrando que a irrigação foi por aspersão e ocorreram várias chuvas, principalmente no final do ciclo deste experimento 1 (446,5 $\mathrm{mm})$. 
Figura 1. Teores de enxofre em $\mathrm{mg} \mathrm{dm}^{-3}$ de solo ao final do ciclo, em função das doses e fontes de potássio aplicados em cobertura no experimento 1 (15/07 a 22/11/2010). São Manuel-SP. 2010.

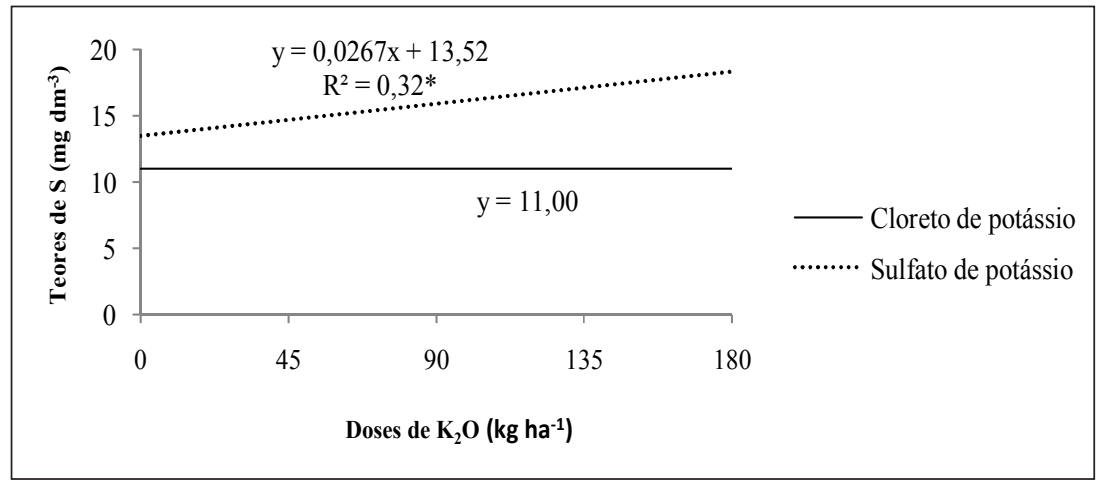

Fonte: Elaboração pelos autores.

Com relação aos teores de macronutrientes na planta ao final do ciclo no experimento 1 , não se observou diferença para os teores de $\mathrm{N}, \mathrm{P}, \mathrm{Ca}$ e $\mathrm{Mg}$ tanto para doses como para fontes de potássio, com médias de 24,5 ( $\mathrm{CV}=12,6 \%), 3,5(\mathrm{CV}=9,8 \%)$, $5,6(\mathrm{CV}=16,7 \%)$ e $2,5(\mathrm{CV}=14,4 \%) \mathrm{g} \cdot \mathrm{kg}^{-1} \mathrm{de}$ matéria seca, respectivamente. Portanto, mesmo nas maiores doses de potássio não houve interferência na absorção de outros nutrientes catiônicos (cálcio e magnésio), conforme observado por Araújo (2011) estudando doses de potássio em cobertura em abobrinha-de-moita. Talvez o fato de o potássio ter sido fornecido aos poucos em cobertura e a provável lixiviação do mesmo, não devem ter interferido na absorção dos outros cátions. Porém, observou-se maior concentração de potássio na planta quanto maior a dose de cloreto de potássio (Figura 2), o que também foi relatado por Araújo (2011) estudando adubação potássica em cobertura em abobrinha-demoita. Já para o sulfato de potássio a resposta foi quadrática, com máximo estimado para a dose de $105 \mathrm{~kg} \mathrm{ha}^{-1}$ de $\mathrm{K}_{2} \mathrm{O}$. Porém, esta maior absorção de $\mathrm{K}$ não resultou em maior produção e, aparentemente, em diferença na incidência da podridão negra, talvez caracterizando uma absorção de luxo pela planta, conforme destacado por Fernandes (2006).

Figura 2. Teores de potássio na matéria seca da planta de repolho, em função das doses e fontes de potássio aplicados em cobertura no experimento 1 (15/07 a 22/11/2010). São Manuel-SP. 2010.

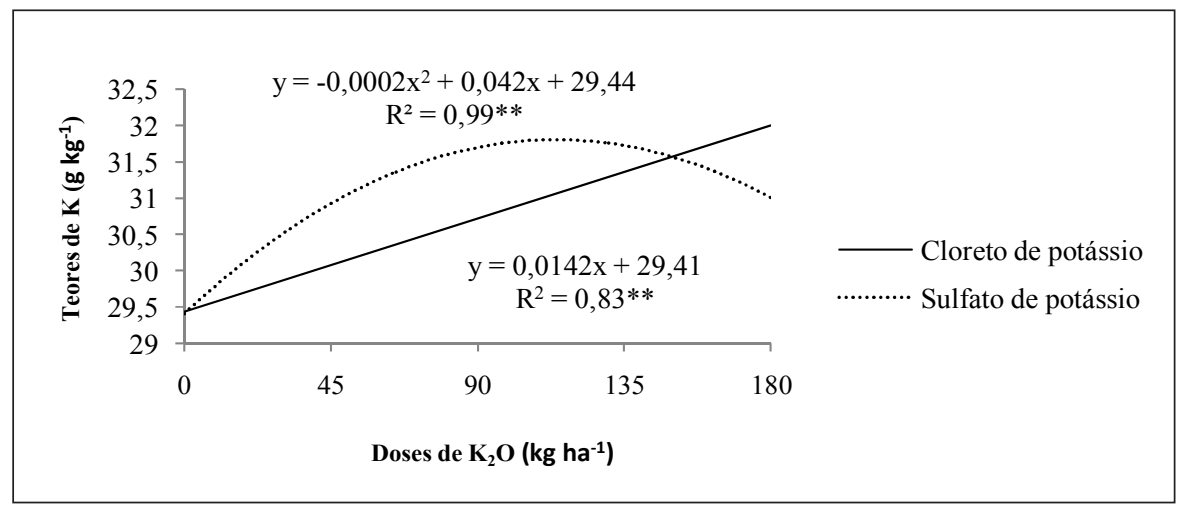

Fonte: Elaboração pelos autores. 
Com relação ao enxofre, a aplicação de cloreto de potássio não afetou o teor deste nutriente nas folhas, com média de $8,78 \mathrm{~g} \mathrm{~kg}^{-1}$ de matéria seca. Porém, observou-se aumento linear no teor deste nutriente quanto maior a dose de sulfato de potássio (Figura
3). Estes resultados são coerentes, pois o cloreto não é fonte de enxofre, enquanto que quanto maior a dose de sulfato de potássio, maior a quantidade de enxofre aplicado em cobertura.

Figura 3. Teores de enxofre na matéria seca da planta de repolho, em função das doses e fontes de potássio aplicados em cobertura no experimento 1 (15/07 a 22/11/2010). São Manuel-SP. 2010.

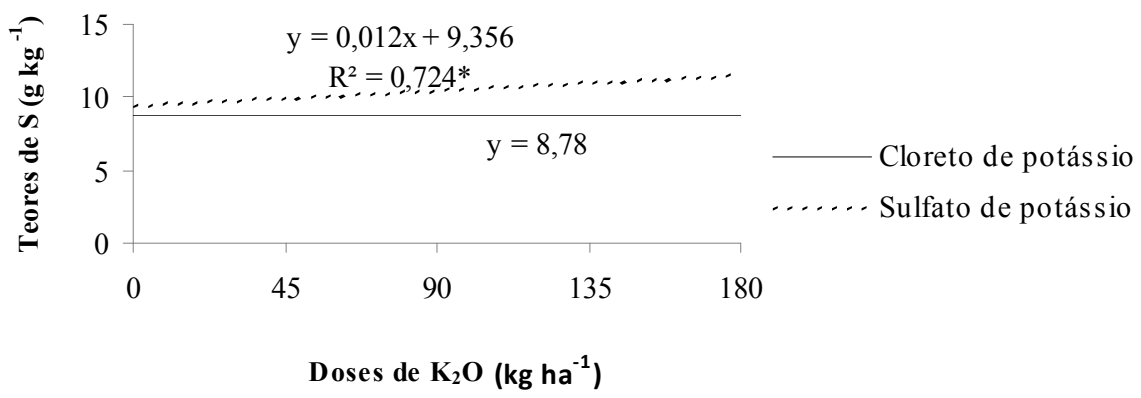

Fonte: Elaboração pelos autores.

Comparando-se os macronutrientes no experimento 1, observa-se a seguinte ordem decrescente no teor nas folhas: $\mathrm{K}>\mathrm{N}>\mathrm{S}>\mathrm{Ca}>$ $\mathrm{P}>\mathrm{Mg}$. Portanto, o potássio foi o nutriente mais absorvido pelo repolho e o enxofre foi o terceiro, mostrando a importância destes para a cultura, mesmo na testemunha sem aplicação de K e S em cobertura. Já Aquino et al. (2009) obtiveram a seguinte ordem: $\mathrm{K}>\mathrm{N}>\mathrm{Ca}>\mathrm{S}>\mathrm{P}>\mathrm{Mg}$, confirmando que o $\mathrm{K}$ foi o nutriente com maior teor nas folhas e, portanto, mais extraído. Avalhães et al. (2009) também relataram maior teor de K (63,5 $\mathrm{g} \mathrm{kg}^{-1}$ ) em repolho. Quanto ao S, também Magro, Cardoso e Fernades (2009) relataram elevado teor em sementes de brócolis, sendo o segundo nutriente mais acumulado, confirmando a elevada extração deste pelas culturas da espécie Brassica oleracea. No entanto, apesar da exigência da cultura, as doses de cloreto e sulfato de potássio não afetaram a produção, talvez pela eficiência da cultura na absorção dos mesmos e do fato de se ter fornecido no plantio NPK e matéria orgânica, que é fonte de potássio e enxofre. Quanto aos micronutrientes avaliados no experimento 1, não foram observadas diferenças nos teores nem em função das doses nem fontes de potássio. A ordem decrescente de valores foi: $\mathrm{Fe}>\mathrm{B}>\mathrm{Mn}>\mathrm{Zn}>\mathrm{Cu}$, com valores médios de $57,7,33,7,20,7,19,8$ e 2,6 mg kg-1 de matéria seca. A mesma ordem dos micronutrientes foi observada em plantas de brócolis de cabeça única (VARGAS et al., 2007).

$\mathrm{Na}$ comparação com os teores relatados por Raij et al. (1997) como faixas de teores adequados, observa-se que os valores para nitrogênio (adequado 30 a $50 \mathrm{~g} \mathrm{~kg}^{-1}$ de massa seca), fósforo (4 a $7 \mathrm{~g} \mathrm{~kg}^{-1}$ de massa seca) e $\mathrm{Mg}$ (4 a $7 \mathrm{~g} \mathrm{~kg}^{-1}$ de massa seca) estão abaixo desta faixa, provavelmente porque nesta pesquisa avaliou-se a planta inteira ao final do ciclo e não apenas a folha diagnose, que é uma folha em pleno desenvolvimento, sem ter translocado para as folhas mais novas em formação. No final do ciclo estão misturadas folhas novas e velhas que já translocaram estes nutrientes móveis na planta. Já para o enxofre, os valores observados (9 a $11 \mathrm{~g}$ $\mathrm{kg}^{-1}$ de massa seca) são bem superiores ao relatado no Boletim 100 por Raij et al. (1997) em repolho. 
Quanto aos micronutrientes avaliados $(\mathrm{B}, \mathrm{Cu}, \mathrm{Fe}$, $\mathrm{Mn}$ e $\mathrm{Zn}$ ) não foram observadas diferenças nos teores nem com relação às doses nem fontes de potássio. A ordem decrescente de valores foi: ferro $>$ boro $>$ manganês $>$ zinco $>$ cobre, com médias de 57,$6 ; 33,7 ; 20,7 ; 19,8$ e 2,6 $\mathrm{mg} \mathrm{kg}^{-1}$, respectivamente. Comparando-se com os valores considerados adequados por Raij et al. (1997) em repolho, observa-se que apenas para os dois primeiros (ferro e boro) os valores se encontram dentro desta faixa considerada ideal.

O correto manejo da aplicação de potássio no solo é essencial para uma atividade produtiva consciente, que visa adequada produtividade e qualidade do produto, com respeito ao meio ambiente, pois excesso de adubação com potássio pode acarretar contaminação do lençol freático pela lixiviação (ERNANI; ALMEIDA; SANTOS, 2007), além de aumentar o custo de produção.

Portanto, na presente pesquisa não se observou vantagem na aplicação de potássio, assim como enxofre, em cobertura na cultura do repolho. Provavelmente, em solos com teores baixos e médios de potássio apenas a adubação básica no plantio com NPK associada à adubação orgânica pode ser suficiente para suprir as necessidades da cultura.

\section{Agradecimentos}

À FAPESP, pela concessão de bolsa de Iniciação Científica à primeira autora.

\section{Referências}

AQUINO, L. A.; PUIATTI, M.; LÉLIS, M. M.; PEREIRA, P. R. G.; PEREIRA, F. H. F. Produção de biomassa, teor e exportação de macronutrientes em plantas de repolho em função de doses de nitrogênio e de espaçamentos. Ciência e Agrotecnologia, Lavras, v. 33, n. 5, p. 1295-1300, 2009.

AQUINO, L. A.; PUIATTI, M.; PEREIRA, P. R. G.; PEREIRA, F. H. F.; CASTRO, M. R. S.; LADEIRA, I. R. Características produtivas do repolho em função do espaçamento e doses de nitrogênio. Horticultura Brasileira, Brasília, v. 23, n. 2, p. 266-270, 2005a.

AQUINO, L. A.; PUIATTI, M.; PEREIRA, P. R. G.; PEREIRA, F. H. F.; LADEIRA, I. R.; CASTRO, M. R. $\mathrm{S}$. Efeito de espaçamentos e doses de nitrogênio sobre as características qualitativas da produção do repolho. Horticultura Brasileira, Brasília, v. 23, n. 1, p. 100-104, 2005b.

ARAÚJO, H. S. Doses de potássio em cobertura na produção e qualidade de frutos de abobrinha-demoita. 2011. Dissertação (Mestrado em Horticultura) - Faculdade de Ciências Agronômicas. Universidade Estadual Paulista, Botucatu.

AVALHÃES, C. C.; PRADO, R. M.; ROMUALDO, L. M.; ROZANE, D. E.; CORREIA, M. A. R. Omissão de macronutrientes no crescimento e no estado nutricional de plantas de repolho cultivado em solução nutritiva. Bioscience Journal, Uberlândia, v. 25, n. 5, p. 21-28, 2009.

CAVARIANNI, R. L. Densidade de plantio e doses de nitrogênio no desenvolvimento e produção de repolho. 2008. Tese (Doutorado em Agronomia) - Faculdade de Ciências Agrárias e Veterinária. Universidade Estadual Paulista, Jaboticabal.

CUNHA, A. R.; MARTINS, D. Classificação climática para os municípios de Botucatu e São Manuel, SP. Irriga, Botucatu, v. 14, n. 1, p. 1-11, 2009.

DIN, M.; QASIM, M.; ALAM, M. Effect of different levels of N, P and K on the growth and yield of cabbage. Journal of Agriculture Research, Lahore, v. 45, n. 2, p. 171-176, 2007.

ERNANI, P. R.; ALMEIDA, J. A.; SANTOS, F. C. Potássio. In: NOVAIS, R. F.; ALVAREZ, V. H.; BARROS, N. F.; FONTES, R. L.; CANTARUTTI, R. B.; NEVES, J. C. L. (Org.). Fertilidade do solo. Viçosa: Sociedade Brasileira de Ciência do Solo, 2007. v. 1, p. 551-594.

FERNANDES, M. S. Nutrição mineral de plantas. Viçosa: Sociedade Brasileira de Ciências do Solo, 2006. $432 \mathrm{p}$.

FILGUEIRA, F. A. R. Novo manual de olericultura: agrotecnologia moderna na produção e comercialização de hortaliças. Viçosa: Universidade Federal de Viçosa, 2008. $421 \mathrm{p}$.

HIGUTI, A. R. O.; SALATA, A. C.; GODOY, A. R.; CARDOSO, A. I. I. Produção de mudas de abóbora com diferentes doses de nitrogênio e potássio. Bragantia, Campinas, v. 69, n. 2, p. 377-380, 2010. 
HUETT, D. O.; DETTMANN, E. B. Effect of nitrogen on growth,quality and nutrient uptake of cabbages grown in sand culture. Australian Journal of Experimental Agriculture, Collingwood, v. 29, n. 6, p. 875-881, 1989.

KIEHL, E. J. Fertilizantes orgânicos. Piracicaba: Agronômica Ceres, 1985. 492 p.

LUZ, J. M. Q.; FILHO, A. Z.; RODRIGUES, W. L.; RODRIGUES, C. R.; QUEIROZ, A. A. Adubação de cobertura com nitrogênio, potássio e cálcio na produção comercial de cenoura. Horticultura Brasileira, Brasília, v. 27, n. 4 , p. 543-548, 2009.

MAGRO, F. O.; ARRUDA, N.; CASA, J.; SALATA, A. C.; CARDOSO, A. I. I.; FERNANDES, D. M. Composto orgânico na produção e qualidade de sementes de brócolis. Ciência e Agrotecnologia, Lavras, v. 34, n. 3, p. 596-602, 2010.

MAGRO, F. O.; CARDOSO, A. I. I.; FERNANDES, D. M. Acúmulo de nutrientes em sementes de brócolis em função de doses de composto orgânico. Cultivando o Saber, Cascavel, v. 2, n. 4, p. 49-57, 2009.

MALAVOLTA, E.; VITTI, G. C.; OLIVEIRA, S. A. Avaliação do estado nutricional das plantas: princípios e aplicações. 2. ed. Piracicaba: Potafós, 1997. 319 p.

MOREIRA, M. A.; VIDIGAL, S. M.; SEDIYAMA, M. A. N.; SANTOS, M. R. Crescimento e produção de repolho em função de doses de nitrogênio. Horticultura Brasileira, Brasília, v. 29, n. 1, p. 117-121, 2011.

MOREIRA, M. A.; VIDIGAL, S. M. Evolução das características da planta associadas à nutrição nitrogenada de repolho. Ceres, Viçosa, v. 58, n. 2, p. 243-248. 2011.

NAHAS, E.; DELFINO, J. H.; ASSIS, L. C. Atividade microbiana e propriedades bioquímicas do solo resultantes da aplicação de gesso agrícola na cultura do repolho. Scientia Agricola, Piracicaba, v. 54, n. 3, p. 160166, 1997.
OLIVEIRA, F. L.; RIBAS, R. G. T.; JUNQUEIRA, R. M.; PADOVAN, M. P.; GUERRA, J. G. M.; ALMEIDA, D. L.; RIBEIRO, R. L. D. Uso do pré-cultivo de Crotalaria juncea e de doses crescentes de "cama" de aviário na produção do repolho sob manejo orgânico. Agronomia, Seropédica, v. 37, n. 2, p. 60-66, 2003.

PERUCH, L. A. M.; MICHEREFF, S. J.; ARAÚJO, I. B. Levantamento da intensidade da alternariose e da podridão negra em cultivos orgânicos de brássicas em Pernambuco e Santa Catarina. Horticultura Brasileira, Brasília, v. 24, n. 4, p. 464-469, 2006.

RAIJ, B. van; CANTARELLA, H.; QUAGGIO, J. A.; FURLANI, A. M. C. Recomendações de adubação e calagem para o estado de São Paulo. 2. ed. Campinas: Instituto Agronômico e Fundação IAC, 1997. 285 p.

RAIJ, B. van; QUAGGIO, J. A. Métodos de análises de solo para fins de fertilidade. Campinas: Instituto Agronômico, 1983. 31 p. (Boletim técnico, 81).

SALATA, A. C.; GODOY, A. R.; KANO, C.; HIGUTI, A. R. O.; CARDOSO, A. I. I.; EVANGELISTA, R. M. Produção e qualidade de frutos de ervilha torta submetidas a diferentes níveis de adubação potássica. Nucleus, Ituverava, v. 8, n. 2, p. 127-134, 2011.

SILVA, G. S.; CECÍlIO FILHO, A. B.; BARBOSA, J. C.; ALVES, A. U. Espaçamentos entre linhas e entre plantas no crescimento e na produção de repolho roxo. Bragantia, Campinas, v. 70, n. 3, p. 538-543, 2011.

VARGAS, P. F.; CASTOLDI, R.; CHARLO, H. C. O.; BRAZ, L. T. Acúmulo e exportação de micronutrientes durante o ciclo de couve brócolos 'Legacy'. In: CONGRESSO BRASILEIRO DE OLERICULTURA, 47., 2007, Porto Seguro. Anais... Porto Seguro: ABH, 2007a. 1 CD-ROM. 
